
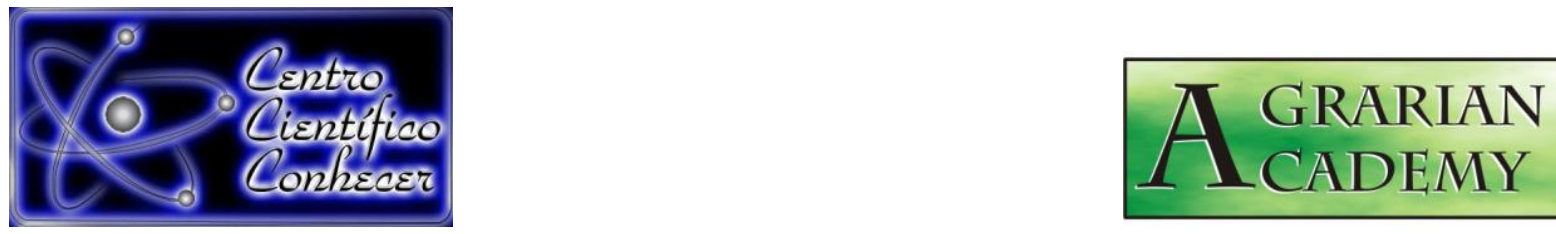

\title{
DESENVOLVIMENTO INICIAL DA CEVADA INOCULADA COM Azospirillum brasilense EM COMPETIÇÃO COM POPULAÇÕES DE AZEVÉM
}

\author{
Willian Pies ${ }^{1}$, Tadeu Werlang ${ }^{2}$, Ana Caroline Pereira da Luz², Marco Aurélio \\ Tramontin ${ }^{3}$; Siumar Pedro Tironi ${ }^{3}$ \\ ${ }^{1}$ Acadêmico do curso de Agronomia, Universidade Federal da Fronteira Sul, campus \\ Chapecó-SC, Brasil. E-mail: willian_pies@hotmail.com. \\ ${ }^{2}$ Acadêmico do curso de Agronomia, Universidade Federal da Fronteira Sul, campus \\ Chapecó-SC, Brasil. \\ ${ }^{3}$ Professor do curso de Agronomia da Universidade Federal da Fronteira Sul, campus \\ Chapecó-SC, Brasil.
}

Recebido em: 30/11/2017 - Aprovado em: 15/12/2017 - Publicado em: 31/12/2017 DOI: 10.18677/Agrarian Academy 2017b28

\begin{abstract}
RESUMO
A competição exercida pelas plantas daninhas, como o azevém, destaca-se como um limitante ao desenvolvimento da cevada. O uso de inoculantes à base de bactérias promotoras de crescimento pode se tornar uma alternativa para melhorar o desenvolvimento das plantas e seu potencial competitivo. Dentre as principais encontra-se o gênero Azospirillum que é caracterizada como fixadora de nitrogênio. Objetivou-se avaliar a eficiência da inoculação de estirpes $A$. brasilense e de densidades de azevém nos estádios iniciais da cultivar BRS Korbel. Utilizou-se delineamento inteiramente casualizado, sendo que os tratamentos utilizados foram: inoculação ou não de Azospirillum brasiliense (primeiro fator) e populações de azevém (segundo fator). Durante a fase vegetativa da cultura foram realizadas as quantificações de estatura das plantas, teor de clorofila (índice SPAD), perfilhamento, massa seca da parte aérea e raiz, comprimento das raízes e volume de raízes. Da espécie daninha foram avaliados o número de perfilhos e massa seca da parte aérea. Através dos dados realizou-se a análise estatística (Duncan $p \leq 0,05)$. A inoculação favoreceu o perfilhamento e comprimento radicular da cultura. O aumento das populações da daninha acarretou na redução das variáveis: altura, perfilhamento, teor de clorofila, comprimento, volume e massa seca das raízes da cevada. A inoculação não contribui para a elevação da competitividade da cultura.
\end{abstract}

PALAVRAS-CHAVE: Bactéria diazotrófica, Hordeum vulgare, Lolium multiflorum.

\section{INITIAL DEVELOPMENT OF BARLEY INOCULATED WITH AZOSPIRILLUM BRASILENSE IN COMPETITION WITH POPULATIONS OF RYEGRASS}

\begin{abstract}
Competition from weeds, such as ryegrass, stands out as a constraint on the development of barley. The use of inoculants based on growth-promoting bacteria may become an alternative to improve plant development and its competitive
\end{abstract}


potential. Among the main ones is the genus Azospirillum, which is characterized as nitrogen fixation. The objective of this study was to evaluate the efficiency of inoculation of $A$. brasilense strains and ryegrass densities in the early stages of cultivar BRS Korbel. A completely randomized design was used, with the following treatments: inoculation or not of Azospirillum brasiliense (first factor) and ryegrass populations (second factor). During the vegetative phase of the crop, the measurements of plant height, chlorophyll content (SPAD index), tillering, dry mass of shoot and root, length of roots and root volume were performed. The number of tillers and dry mass of the shoot were evaluated. Statistical analysis was performed using the data (Duncan - $\mathrm{p} \leq 0.05$ ). The inoculation favored tillering and root length of the crop. The increase in weed populations led to a reduction in the variables: height, tillering, chlorophyll content, length, volume and dry weight of barley roots. Inoculation does not contribute to the increase of the competitiveness of the crop.

KEYWORDS: Diazotrophic bacteria, Hordeum vulgare, Lolium multiflorum.

\section{INTRODUÇÃO}

A cevada (Hordeum vulgare) é uma espécie que pertence à família Poaceae. Esta cultura é um dos cereais de inverno mais produzidos ao longo dos tempos, os grãos são a principal matéria prima da produção de cerveja (BRUNES et al., 2017). Na safra 2016/2017, a área cultivada com cevada no Brasil foi de aproximadamente 109 mil hectares, concentrados na região sul do país (CONAB, 2017).

A competição exercida pelas plantas daninhas destaca-se como um dos principais limitantes a cultura da cevada, estas acabam por ocasionar a redução em fatores como o desenvolvimento, crescimento e posterior produtividade desta espécie em resposta a menor disponibilidade de recursos essenciais a cultura, tais como $\mathrm{CO}_{2}$, água, luz e nutrientes (AGOSTINETTO et al., 2008).

Dentre as plantas daninhas de maior importância na cultura da cevada destaca-se o azevém (Lolium multiflorum). Este é encontrado com frequência nas lavouras de inverno na região sul do Brasil. A espécie destaca-se como altamente competitiva pelos recursos disponíveis no meio, necessitando de algum método de manejo para evitar perdas quantitativas e qualitativas da cevada (TIRONI et al., 2014). O azevém, mesmo em baixas populações, deve ser controlado na lavoura, pois reduz o afilhamento, a área foliar e a massa seca da parte área da cultura (GALON et al., 2011).

Devido a grande importância da cultura para o mercado brasileiro, é necessário adotar novas tecnologias com a finalidade de reduzir custos e aumentar a produtividade. Assim, estudos sobre o uso de inoculantes à base de bactérias promotoras do crescimento de plantas surgem como uma alternativa (QUADROS et al., 2014). Bactérias do gênero Azospirillum podem ser inoculadas em culturas contribuindo com seu crescimento por múltiplos mecanismos, estas são capazes de colonizar o sistema radicular das plantas, contribuindo para o crescimento vegetal através da produção de fitohormônios como auxinas, giberilinas e citocininas (RICHARDSON et al., 2009; YANG et al., 2009).

Vários são os estudos sobre o efeito da inoculação de Azospirillum brasilense em culturas agrícolas. Na cultura do trigo, a inoculação da bactéria melhorou o teor de clorofila e promoveu o peso das raízes (SILVEIRA et al., 2016), aumentando a altura das plantas e o número de grãos por espiga da cultura (ALVES et al., 2017). No milho, essa bactéria pode aumentar a produtividade de grãos (MORAIS et al., 2016). Nesse sentido, foi conduzido um estudo com objetivo de avaliar o efeito da 
inoculação da bactéria Azospirillum brasilense no desenvolvimento inicial da cevada em competição com diferentes populações de azevém.

\section{MATERIAL E MÉTODOS}

A condução do experimento foi realizada em estufa com ambiente controlado no campus da Universidade Federal da Fronteira Sul, sendo que o arranjo dos tratamentos foi inteiramente casualizado, com quatro unidades experimentais. As unidades experimentais foram compostas por vasos de polipropileno, com volume de $12 \mathrm{dm}^{3}$, preenchidas com solo corrigido $(\mathrm{pH}=6)$ e com níveis altos de fósforo e potássio, sem a realização de adubação. A cultivar estudada foi a BRS Korbel.

Os tratamentos foram constituídos de fatorial $(5 \times 2)$, onde o primeiro fator foram diferentes populações de azévem $(0,4,8,16$ e 32 plantas por vaso) e o segundo com ou sem inoculação de $A$. brasilense. Antes do plantio realizou-se a inoculação de um $\mathrm{mL}$ da bactéria em um $\mathrm{kg}$ de sementes de cevada, deixando-as secar por 20 minutos em local fresco e protegido do sol.

Foram semeadas 15 sementes da cultura por vaso e quantidade suficiente para determinar as populações da daninha. Após a germinação foi efetuado o estabelecimento de 10 plântulas de cevada em cada unidade experimental e quantia de azevém conforme os tratamentos.

A quantificação da altura da cevada foi realizada aos 15, 30, 45 e 60 após o surgimento das plântulas, com régua graduada, medindo do solo até o ápice da última folha, já a mensuração do teor de clorofila (índice SPAD) foi realizado aos 15 e 30 DAE utilizando um clorofilômetro digital (SoilControl, CFL-1030). O número de perfilhos de cevada foi quantificado aos 45, 60 e 65 DAE a partir da contagem de todos os colmos contidos em cada vaso. O número de perfilho do azevém foi quantificado aos $65 \mathrm{DAE}$, com a contagem de todos os colmos contidos em cada vaso e, posteriormente, foi calculado o número de perfilhos.

A massa seca da parte aérea da cevada (MSPAC) e do azevém (MSPAA) foram quantificadas a partir da coleta das plantas cortadas rente ao solo, aos 65 DAE, as plantas foram separadas de acordo com a espécie, alocadas em sacos de papéis e levadas a estufa de circulação forçada de ar com temperatura de $60{ }^{\circ} \mathrm{C}$, e ficaram até atingir massa constante.

No dia da coleta das plantas realizou-se a lavagem das raízes da cevada, sendo que posteriormente foi mensurado o comprimento das raízes com régua graduada. $O$ volume das raízes da cevada foi quantificado mergulhando-as em uma proveta graduada com volume conhecido de água, em que foi quantificada a alteração do volume de água. Em seguida o sistema radicular foi alocado em sacos de papel e levadas a estufa de circulação forçada de ar com temperatura de $60{ }^{\circ} \mathrm{C}$, onde ficaram até obter massa constante para quantificação da massa seca das raízes da cevada.

Os dados coletados foram avaliados quanto à distribuição normal e homocedasticidade. Posteriormente, foram submetidos à análise de variância e Duncan ( $\mathrm{p} \leq 0,05 \%)$ pelo programa WinStat, versão 2.0 (MACHADO ; CONCEIÇÃO, 2005)

\section{RESULTADOS E DISCUSSÕES}

Verificou-se interação dos fatores para a variável : número de perfilhos de azevém, sendo que na densidade de quatro plantas por vaso, observou-se menor número de perfilhos no tratamento com inoculação (Tabela 1), o que denota que a 
associação da $A$. brasilense com a cevada teve influência negativa na formação de novos perfilhos de azevém, sendo que a associação proporcionou maior suporte para a cultura no seu desenvolvimento e capacidade de competir com a daninha (MOLLA; SHARAIHA, 2010).

Observou-se, também, que no tratamento sem inoculação a densidade de quatro plantas proporcionou maior número de perfilhos, dado que nas demais populações ocorreram reduções, isso indica que a planta daninha é afetada quando encontra-se em locais infestados, devido a competição intraespecífica (Tabela 1).

TABELA 1. Número de perfilho de azevém (perfilho por planta) em função de populações de azevém (plantas por vaso ${ }^{1}$ ) e inoculação de Azopirillum.

\begin{tabular}{lcc}
\hline Populações de azevém & \multicolumn{2}{c}{ Inoculação de Azospirillum } \\
\cline { 2 - 3 } & Com & Sem \\
\hline $\mathbf{0}$ & $0,00 \mathrm{cA}^{*}$ & $0,00 \mathrm{cA}^{*}$ \\
$\mathbf{4}$ & $1,69 \mathrm{abB}$ & $3,19 \mathrm{aA}$ \\
$\mathbf{8}$ & $2,12 \mathrm{aA}$ & $1,75 \mathrm{bA}$ \\
$\mathbf{1 6}$ & $1,77 \mathrm{abA}$ & $1,72 \mathrm{bA}$ \\
$\mathbf{3 2}$ & $1,51 \mathrm{bA}$ & $1,36 \mathrm{bA}$ \\
$\mathbf{C V}(\%)$ & & 18,00 \\
\hline
\end{tabular}

${ }^{1}$ Vaso de $12 \mathrm{dm}^{3}$ de superfície. *As médias seguidas de mesma letra, minúscula na coluna e maiúscula na linha, não diferem pelo teste Duncan $(p \leq 0,05)$.

Na variável massa seca da parte aérea da cevada (MSPAC) também ocorreu interação entre os fatores, sendo que houve reduções na massa seca da parte aérea da cevada nas maiores populações de plantas daninhas, sem influência da inoculação (Tabela 2). Esses resultados corroboram com Galon et al. (2011), em que é relatada a diminuição da massa seca da cevada quando a mesma competiu com azevém. Também verificou-se que no tratamento com quatro plantas de azevém, a inoculação da bactéria contribuiu para maior incremento MSPAC em comparação a não inoculação, já na testemunha, a não inoculação apresentou maior incremento (Tabela 2).

A MSPAC apresenta redução conforme se tem aumento das populações de azevém (Tabela 2), evidenciando que maiores populações ocasionam reduções significativas na formação da parte aérea da cultura.

TABELA 2. Massa seca da parte aérea da cevada - MSPAC ( $\left(g\right.$ vaso $\left.^{-1}\right)$ em função de populações de azevém (plantas por vasoํ) e inoculação de Azospirillum.

\begin{tabular}{lcc}
\hline \multirow{2}{*}{ Populações de azevém } & \multicolumn{2}{c}{ Inoculação de Azospirillum } \\
\cline { 2 - 3 } & Com & Sem \\
\hline $\mathbf{0}$ & $13,38 \mathrm{abcB}$ & $16,90 \mathrm{aA}^{\star}$ \\
$\mathbf{4}$ & $15,12 \mathrm{aA}$ & $11,99 \mathrm{bB}$ \\
$\mathbf{8}$ & $14,39 \mathrm{abA}$ & $12,71 \mathrm{bA}$ \\
$\mathbf{1 6}$ & $11,53 \mathrm{bcA}$ & $12,19 \mathrm{bA}$ \\
$\mathbf{3 2}$ & $10,74 \mathrm{cA}$ & $12,49 \mathrm{bA}$ \\
$\mathbf{C V}(\%)$ & & 13,57 \\
\hline
\end{tabular}

${ }^{1}$ Vaso de $12 \mathrm{dm}^{3}$ de superfície. *As médias seguidas de letras iguais minúsculas na coluna e letras iguais maiúsculas na linha não diferem entre si pelo teste Duncan $(p \leq 0,05)$.

Em estudo realizado por Hungria et al. (2016), a aplicação de nitrogênio (N) associado com a inoculação da bactéria $A$. brasilense proporcionou maior incremento de biomassa em duas espécies de Brachiaria. Vogel et al. (2014) 
salientam que estudos no Brasil demonstram sucesso na inoculação de Azospirillum em gramíneas forrageiras.

Houve interação entre os fatores para a altura da cevada nos 60 DAE (Tabela 3), sendo que a inoculação da bactéria promoveu menor altura de plantas no tratamento sem competição e com oito plantas da daninha. Em relação ao aumento das populações de azevém, observou-se que não ocorreu diferença nas alturas das plantas inoculadas, já nas plantas sem inoculação, a testemunha apresentou-se superior as demais, que não diferiram entre si (Tabela 3). Segundo Paynter e Hills (2009) a convivência da cevada com azevém pode retardar o fechamento do dossel da cultura e reduzir a altura das plantas de cevada após o alongamento do caule, porém nos tratamentos com inoculação o $A$. brasilense proporcionou melhores condições de desenvolvimento fazendo com que não ocorresse diferença nas alturas.

TABELA 3. Altura da cevada (cm) aos 60 dias após a emergência (DAE) em função de populações de azevém (plantas por vaso ${ }^{1}$ ) e inoculação de Azospirillum.

\begin{tabular}{|c|c|c|}
\hline \multirow{2}{*}{ Populações de azevém } & \multicolumn{2}{|c|}{ Inoculação de Azospirillum } \\
\hline & Com & Sem \\
\hline 0 & $28,04 \mathrm{aB}^{*}$ & $32,94 \mathrm{aA}^{*}$ \\
\hline 4 & 29,77 aA & $28,30 \mathrm{bA}$ \\
\hline 8 & $26,90 \mathrm{aB}$ & $29,52 \mathrm{bA}$ \\
\hline 16 & 27,37 aA & $29,54 \mathrm{bA}$ \\
\hline 32 & 27,92 aA & $29,42 \mathrm{bA}$ \\
\hline CV (\%) & & \\
\hline
\end{tabular}

${ }^{1}$ Vaso de $12 \mathrm{dm}^{3}$ de superfície. *As médias seguidas das mesmas letras, minúscula na coluna e maiúscula na linha, não diferem entre si pelo teste Duncan $(p \leq 0,05)$.

Nas avaliações das alturas dos 15, 30 e 45 DAE, verificou-se que as menores alturas foram mensuradas nos tratamentos em que a cultura estava convivendo com altas populações da daninha, sendo que em geral houve decréscimo da altura com o aumento das populações. Segundo Galon et al. (2011) mesmo com baixa densidade de azevém ocorre redução no perfilhamento, área foliar e, consequentemente, menor desenvolvimento das plantas de cevada. Em relação a inoculação ou não de A. brasilense, observou-se que a inoculação prejudicou o desenvolvimento da cevada quando avaliada aos $45 \mathrm{DAE}$, não apresentando diferença nas avaliações aos 15 e 30 DAE (Tabela 4).

TABELA 4. Altura das plantas de cevada (cm) aos 15, 30 e 45 dias após a emergência (DAE), em função de populações (plantas por vaso ${ }^{1}$ ) de azevém e inoculação de Azospirillum.

\begin{tabular}{llll}
\hline Populações de azevém & 15 DAE & 30 DAE & 45 DAE \\
\hline $\mathbf{0}$ & $13,67 \mathrm{AB}^{*}$ & $26,30 \mathrm{~A}^{*}$ & $31,39 \mathrm{~A}^{*}$ \\
$\mathbf{4}$ & $14,16 \mathrm{~A}$ & $25,38 \mathrm{AB}$ & $29,30 \mathrm{~B}$ \\
$\mathbf{8}$ & $12,51 \mathrm{BC}$ & $23,84 \mathrm{BC}$ & $28,80 \mathrm{~B}$ \\
$\mathbf{1 6}$ & $13,09 \mathrm{AB}$ & $23,22 \mathrm{C}$ & $28,60 \mathrm{~B}$ \\
$\mathbf{3 2}$ & $11,47 \mathrm{C}$ & $22,92 \mathrm{C}$ & $28,18 \mathrm{~B}$ \\
\hline Inoculação com A. brasilense & & & \\
\hline Inoculado & $13,15^{\mathrm{ns}}$ & $24,24^{\mathrm{ns}}$ & $28,60 \mathrm{~B}^{*}$ \\
Não inoculado & 12,97 & 24,71 & $30,08 \mathrm{~A}$ \\
\hline
\end{tabular}

${ }^{1}$ Vaso de $12 \mathrm{dm}^{3}$ de superfície. ${ }^{n s}$ Médias não significativas para o teste de Duncan $(p \leq 0,05) .{ }^{*}$ As letras maiúsculas iguais nas colunas não apresentam diferença estatística segundo Duncan $(p \leq 0,05)$.

AGRARIAN ACADEMY, Centro Científico Conhecer - Goiânia, v.4, n.8; p.271 2017 
O teor de clorofila das folhas de cevada não foi influenciado por ambos os fatores analisados aos $15 \mathrm{DAE}$, na análise de $30 \mathrm{DAE}$ somente as densidades de azevém interferiram no teor de clorofila. As reduções no teor de clorofila ocorreram a partir das densidades de 16 plantas por vaso (Tabela 5). O azevém é uma espécie com elevado potencial competitivo (TIRONI et al., 2014), o que pode ter diminuído os recursos do meio, como o nitrogênio, elemento importante nas moléculas de clorofila (VESALI et al., 2017).

TABELA 5. Teor de clorofila das folhas de cevada (vaso-1) aos 15 e 30 dias após e emergência (DAE) em função de populações (plantas por vaso') de azevém e inoculação de Azospirillum.

\begin{tabular}{lll}
\hline $\begin{array}{l}\text { Densidades de azevém } \\
\text { (plantas por vaso1) }\end{array}$ & 15 DAE & 30 DAE \\
\hline $\mathbf{0}$ & $26,68^{\mathrm{ns}}$ & $48,85 \mathrm{~A}^{*}$ \\
$\mathbf{4}$ & 25,95 & $46,82 \mathrm{~A}$ \\
$\mathbf{8}$ & 26,40 & $46,02 \mathrm{AB}$ \\
$\mathbf{1 6}$ & 28,44 & $40,74 \mathrm{C}$ \\
$\mathbf{3 2}$ & 23,77 & $42,04 \mathrm{BC}$ \\
\hline Inoculação com A. brasilense & & \\
\hline Inoculado & $27,31^{\mathrm{ns}}$ & $46,38^{\mathrm{ns}}$ \\
Não inoculado & 25,22 & 44,19
\end{tabular}

${ }^{1}$ Vaso de $12 \mathrm{dm}^{3}$ de superfície. ns Médias não significativas para o teste de Duncan $(p \leq 0,05)$. ${ }^{\star}$ Médias seguidas por letras iguais na coluna, dentro de cada fator, não diferem significativamente pelo teste de Duncan $(p \leq 0,05)$.

A inoculação da bactéria proporcionou um aumento no perfilhamento da cevada nas avaliações aos 45 e 65 DAE, destacando-se na análise de 45 DAE em que houve um aumento de $17 \%$ no número de perfilhos (Tabela 6). O maior perfilhamento da cevada devido à inoculação da bactéria está relacionado com os benefícios que a bactéria gera para a cultura, como uma maior expressão nos genes das plantas que estão envolvidos na absorção de nutrientes o que aumenta a aquisição de nutrientes por parte das culturas (CAMILIOS-NETO et al., 2014).

TABELA 6. Número de perfilhos por planta de cevada aos 45, 60 e 65 dias após e emergência (DAE vaso-1) em função de populações (plantas por vaso') de azevém e inoculação de Azospirillum.

\begin{tabular}{lccc}
\hline Densidades de azevém & $\mathbf{4 5} \mathrm{DAE}$ & $\mathbf{6 0} \mathrm{DAE}$ & $\mathbf{6 5} \mathrm{DAE}$ \\
\hline $\mathbf{0}$ & $3,35 \mathrm{~A}^{*}$ & $4,27 \mathrm{~A}^{*}$ & $4,12 \mathrm{~A}^{*}$ \\
$\mathbf{4}$ & $2,97 \mathrm{~B}$ & $3,92 \mathrm{~A}^{*}$ & $3,64 \mathrm{~B}$ \\
$\mathbf{8}$ & $2,75 \mathrm{BC}$ & $3,82 \mathrm{~A}$ & $3,22 \mathrm{BC}$ \\
$\mathbf{1 6}$ & $2,55 \mathrm{CD}$ & $3,25 \mathrm{~B}$ & $2,97 \mathrm{C}$ \\
$\mathbf{3 2}$ & $2,38 \mathrm{D}$ & $2,92 \mathrm{~B}$ & $2,43 \mathrm{D}$ \\
\hline Inoculação com A. brasilense & & & \\
\hline Inoculado & $3,11 \mathrm{~A}^{*}$ & $3,88^{\mathrm{ns}}$ & $3,56 \mathrm{~A}^{*}$ \\
Não inoculado & $2,57 \mathrm{~B}$ & 3,51 & $3,11 \mathrm{~B}$ \\
\hline
\end{tabular}

${ }^{1}$ Vaso de $12 \mathrm{dm}^{3}$ de superfície. Ns Médias não significativas para o teste de Duncan $(p \leq 0,05)$. ${ }^{*}$ Médias seguidas por letras iguais na coluna, dentro de cada fator, não diferem significativamente pelo teste de Duncan $(p \leq 0,05)$.

O número de perfilhos da cevada diminui com o aumento das densidades de azevém (Tabela 6). Nas avaliações realizadas aos 45 e 65 DAE houve uma redução AGRARIAN ACADEMY, Centro Científico Conhecer - Goiânia, v.4, n.8; p.272 2017 
significativa a partir de quatro plantas por vaso. Na comparação da testemunha, sem azevém, com o tratamento com 32 plantas por vaso, as reduções foram de $29 \%$, $32 \%$ e $41 \%$ para as análises aos 45, 60 e 65 DAE, respectivamente. O azevém tem maior velocidade de desenvolvimento inicial e aumento de emissão de perfilhos em comparação com a cevada, o que pode diminuir a quantidade e qualidade da luz que incide na cultura, reduzindo assim o número de perfilhos da cultura (GALON et al., 2011; TIRONI et al., 2014).

Quanto ao sistema radicular, observou-se que a inoculação de $A$. brasilense promoveu aumento do comprimento das raízes da cevada, porém não influenciou no volume e na massa seca das raízes (Tabela 7). Esses efeitos podem estar associados a capacidade da bactéria em promover o aumento da disponibilização de alguns nutrientes para as plantas, como o nitrogênio e o fósforo, o que pode ter promovido o crescimento radicular (GALINDO et al., 2016; GALINDO et al., 2017). De acordo com Silveira et al. (2016), a inoculação com $A$. brasilense promove o crescimento das raízes de trigo, pela capacidade das mesmas em sintetizar ácido indolacético e fixar nitrogênio.

A competição com azevém afetou o desenvolvimento radicular da cevada, reduzindo respectivamente em 15\%, 37\% e 40\% o comprimento, o volume e a massa seca das raízes da cultura quando comparada a testemunha sem azevém e o azevém na densidade de 32 plantas por vaso (Tabela 7). Esses resultados corroboram com Lamego et al. (2015), em que a competição exercida pelo azevém reduziu o comprimento das raízes de trigo. Além da competição por nutrientes, o azevém também possui substâncias alelopáticas que podem ter interferido no crescimento radicular da cevada, fato esse que já foi observado em plantas de trigo, em que houve redução da massa seca das raízes da cultura (AMINI et al., 2011).

TABELA 7. Comprimento $(\mathrm{cm})$, volume $\left(\mathrm{cm}^{3}\right.$ vaso $\left.{ }^{-1}\right)$ e massa seca $\left(\mathrm{g} \mathrm{vaso}^{-1}\right)$ das raízes da cevada em função de populações (plantas por vaso ${ }^{1}$ ) de azevém e inoculação de Azospirillum.

\begin{tabular}{lccc}
\hline Populações de azevém & $\begin{array}{c}\text { Comprimento da } \\
\text { raiz }(\mathbf{c m})\end{array}$ & $\begin{array}{c}\text { Volume da } \\
\text { raiz (ml) }\end{array}$ & $\begin{array}{c}\text { Massa seca } \\
\text { da raiz }(\mathbf{g})\end{array}$ \\
\hline $\mathbf{0}$ & $26,09 \mathrm{~A}^{*}$ & $75,94 \mathrm{~A}^{*}$ & $12,61 \mathrm{~A}^{*}$ \\
$\mathbf{4}$ & $25,16 \mathrm{~A}$ & $62,19 \mathrm{~B}$ & $10,05 \mathrm{~B}$ \\
$\mathbf{8}$ & $24,12 \mathrm{AB}$ & $56,37 \mathrm{BC}$ & $9,29 \mathrm{BC}$ \\
$\mathbf{1 6}$ & $22,97 \mathrm{~B}$ & $51,67 \mathrm{BC}$ & $8,90 \mathrm{BC}$ \\
$\mathbf{3 2}$ & $21,99 \mathrm{~B}$ & $47,67 \mathrm{C}$ & $7,46 \mathrm{C}$ \\
\hline Inoculação com $\boldsymbol{A}$. brasilense & & & \\
\hline Inoculado & $25,24 \mathrm{~A}^{*}$ & $60,92 \mathrm{~ns}$ & $10,21 \mathrm{~ns}$ \\
Não inoculado & $23,25 \mathrm{~B}$ & 58,64 & 9,44 \\
\hline
\end{tabular}

${ }^{1}$ Vaso de $12 \mathrm{dm}^{3}$ de superfície. NsMédias não significativas para o teste de Duncan $(p \leq 0,05)$. ${ }^{*}$ Médias seguidas por letras iguais na coluna, dentro de cada fator, não diferem significativamente pelo teste de Duncan $(p \leq 0,05)$.

A inoculação da cevada não interferiu no acúmulo de matéria seca da parte aérea do azevém (MSPAA). O aumento das populações de azevém ocasionaram acréscimo na MSPAA (Tabela 8), o que é explicado pelo aumento no número de plantas por área da espécie daninha e o elevado potencial competitivo, pois mesmo em altas densidades é capaz de absorver nutrientes e acumular matéria seca (TIRONI et al., 2014). No entanto, a inoculação da cevada com $A$. brasilense não 
promoveu efeito significativo na cultura ao ponto de elevar a habilidade competitiva e suprimir o acúmulo de massa do azevém.

TABELA 8. Análise da massa seca da parte aérea do azevém - MSPAA ( $g$ vaso-1) em função de populações (plantas por vasoํ) de azevém e inoculação de Azospirillum.

\begin{tabular}{|c|c|}
\hline Densidades de azevém & MSPAA (g vaso-1) \\
\hline 0 & $0,00 \mathrm{D}^{*}$ \\
\hline 4 & $0,89 \mathrm{C}$ \\
\hline 8 & $2,03 \mathrm{~B}$ \\
\hline 16 & $2,47 \mathrm{~B}$ \\
\hline 32 & $3,40 \mathrm{~A}$ \\
\hline \multicolumn{2}{|c|}{ Inoculação com A. brasilense } \\
\hline Inoculado & $1,59 \mathrm{~ns}$ \\
\hline Não inoculado & 1,67 \\
\hline
\end{tabular}

\section{CONCLUSÕES}

A inoculação da cevada com Azospirillum brasilense aumentou o perfilhamento e o comprimento radicular da cultura.

O aumento das populações da daninha diminuíram; a altura, o perfilhamento, teor de clorofila das folhas, comprimento, volume e massa seca das raízes da cevada.

A inoculação da cevada com Azospirillum brasilense não contribui, de maneira perceptível, na competitividade da cevada.

O aumento das populações de azevém aumentou a produção de matéria seca da espécie daninha.

\section{REFERÊNCIAS}

ALVES, C. J.; ARF, O.; RAMOS, A. F.; GALINDO, F. S.; NOGUEIRA, L. M. et al. Irrigated wheat subjected to inoculation with Azospirillum brasilense and nitrogen doses as top-dressing. Revista Brasileira de Engenharia Agrícola e Ambiental, v. 21, n. 8, p. 537-542, 2017. Disponível em: <http://dx.doi.org/10.1590/18071929/agriambi.v21n8p537-542>. doi: 10.1590/1807-1929/agriambi.v21n8p537-542.

AGOSTINETTO, D.; RIGOLI, R. P.; SCHAEDLER, C. E.; TIRONI, S. P.; SANTOS, L. S. Período crítico de competição de plantas daninhas com a cultura do trigo. Plantas Daninhas, v.26, n.2, p.271-278, 2008. Disponível em: <www.scielo.br/scielo.php?script=sci_arttext\&pid=S0100-83582008000200003>. doi: 10.1590/S0100-83582008000200003.

AMINI, R.; MAJNOUN-HOSSEINI, N.; EFTEKHARI, M. Evaluating the allelopathic effect of annual ryegrass (Lolium rigidum) on wheat (Triticum aestivum) seedling growth. Journal of Food, Agriculture \& Environment, v. 9, p. 1071-1073, 2011. Disponível

em: $<$ www.researchgate.net/profile/Rouhollah_Amini/publication/259619842_Evaluating_t he_allelopathic_effect_of_annual_ryegrass_Lolium_rigidum_L_on_wheat_Triticum_a 
estivum_L_seedling_growth/links/56890c8908ae1975839a73d4/Evaluating-theallelopathic-effect-of-annual-ryegrass-Lolium-rigidum-L-on-wheat-Triticum-aestivumL-seedling-growth.pdf>.

BRUNES, A. P.; TAVARES, L. C.; DE OlIVEIRA, S.; VILLELLA, F. A. Adubação silicatada via solo em cevada: rendimento e qualidade fisiológica de sementes. Magistra, v. 27, n. 3/4, 2017. Disponível em: <https://magistraonline.ufrb.edu.br/index.php/magistra/article/view/411/220>.

CAMILIOS-NETO, D.; BONATO, P.; WASSEM, R.; TADRA-SFEIR, M. Z.; BRUSAMARELLO-SANTOS, L. C. et al. Dual RNA-seq transcriptional analysis of wheat roots colonized by Azospirillum brasilense reveals up-regulation of nutrient acquisition and cell cycle genes. BMC Genomics, v. 15, n. 1, p. 378, 2014. Disponível em: <https://doi.org/10.1186/1471-2164-15-378>. doi: 10.1186/14712164-15-378.

CONAB - Companhia Nacional de Abastecimento. Acompanhamento de safra brasileira de grãos: v. 4, décimo levantamento julho/2017. CONAB: Brasília, p. 1171, julho 2017. Disponível em: <www.conab.gov.br/>. Acesso em: 27 nov. 2017.

GALINDO, F. S.; TEIXEIRA FILHO, M. C. M.; BUZETTI, S.; SANTINI, J. M. K.; ALVES, C. J. et al. Corn yield and foliar diagnosis affected by nitrogen fertilization and inoculation with Azospirillum brasilense. Revista Brasileira de Ciência do Solo, v. 40, 2016. Disponível em: <http://dx.doi.org/10.1590/18069657rbcs20150364>. doi: 10.1590/18069657rbcs20150364.

GALINDO, F. S.; TEIXEIRA FILHO, M. C. M.; BUZETTI, S.; SANTINI, J. M. K.; ALVES, C. J. et al. Wheat yield in the Cerrado as affected by nitrogen fertilization and inoculation with Azospirillum brasilense. Pesquisa Agropecuária Brasileira, v. 52, n. 9, p. 794-805, 2017. Disponível em: <http://dx.doi.org/10.1590/s0100204x2017000900012>. doi: 10.1590/S0100-204X2017000900012.

GALON, L.; TIRONI, S. P.; ROCHA, P. R. R.; CONCENÇO, G.; SILVA, A. F. et al. Habilidade competitiva de cultivares de cevada convivendo com azevém. Plantas Daninhas, v. 29, n. 04, p. 771-781, 2011. Disponível em: <http://dx.doi.org/10.1590/S0100-83582011000400007>. doi: 10.1590/S010083582011000400007.

HUNGRIA, M.; NOGUEIRA, M. A.; ARAUJO, R. S. Inoculation of Brachiaria spp. with the plant growth-promoting bacterium Azospirillum brasilense: An environmentfriendly component in the reclamation of degraded pastures in the tropics. Agriculture, Ecosystems and Environment, 221, p. 125-131, 2016. Disponível em: <https://doi.org/10.1016/j.agee.2016.01.024>. doi: 10.1016/j.agee.2016.01.024.

LAMEGO, F. P.; REINEHR, M.; CUTTI, L.; AGUIAR, A. C. M.; RIGON, C. A. G. et al. Morphological alterations in wheat, italian ryegrass and radish seedlings when in competition in at the initial stages of growth. Planta Daninha, v. 33, n. 1, p. 13-22, 2015. Disponível em: <http://dx.doi.org/10.1590/S0100-83582015000100002>. doi: 10.1590/S0100-83582015000100002. 
MACHADO, A. A.; CONCEIÇÃO, A. R. Sistema de análise estatística para Windows, WinStat. Versão 2.0. Pelotas: UFPel, 2005.

MOLLA, A.; SHARAIHA, R. K. Competition and resource utilization in mixed cropping of barley and durum wheat under different moisture stress levels. World Journal of Agricultural Sciences, v. 6, n. 6, p. 713-719, 2010. Disponível em: $<$ http://www.idosi.org/wjas/wjas6(6)/14.pdf>.

MORAIS, T. P. D.; BRITO, C. H. D.; BRANDÃO, A. M.; REZENDE, W. S. Inoculation of maize with Azospirillum brasilense in the seed furrow. Revista Ciência Agronômica, v. 47, n. 2, p. 290-298, 2016. Disponível em: <http://ccarevista.ufc.br/seer/index.php/ccarevista/article/view/3001>. doi: 10.5935/1806-6690.20160034.

PAYNTER, B. H; HILLS, A. L. Barley and rigid ryegrass (Lolium rigidum) competition is influenced by crop cultivar and density. Weed Technology, v. 23, p. 40-48, 2009. Disponível em: <https://doi.org/10.1614/WT-08-093.1>. doi: 10.1614/WT-08-093.1.

QUADROS, P. D.; WURDIG ROESCH, L. F.; RÉGIS FERREIRA DA SILVA, P.; MACEDO VIEIRA, V.; DINAEL ROEHRS, D. et al. Desempenho agronômico a campo de híbridos de milho inoculados com Azospirillum. Revista Ceres, v. 61, n. 2, 2014.

Disponível

em: <http://www.ceres.ufv.br/ojs/index.php/ceres/article/view/4097>. doi: 10.1590/S0034737X2014000200008.

RICHARDSON, A. E.; BAREA, J. M.; MCNEILL, A. M.; PRIGENT-COMBARET, C. Acquisition of phosphorus and nitrogen in the rhizosphere and plant growth promotion by microorganisms. Plant and Soil, v. 321, n. 1-2, p. 305-339, 2009. Disponível em: <https://link.springer.com/article/10.1007/s11104-009-9895-2>. doi: 10.1007/s11104-009-9895-2.

SILVEIRA, A. P. D.; SALA, V. M. R.; CARDOSO, E. J. B. N.; LABANCA, E. G.; CIPRIANO, M. A. P. Nitrogen metabolism and growth of wheat plant under diazotrophic endophytic bacteria inoculation. Applied Soil Ecology, v. 107, p. 313319, 2016. Disponível em: <https://doi.org/10.1016/j.apsoil.2016.07.005>. doi: 10.1016/j.apsoil.2016.07.005.

TIRONI, S. P.; GALON, L.; FERREIRA DA SILVA, A.; TEIXEIRA FIALHO, C. M.; RIBEIRO ROCHA, P. R. et al. Época de emergência de azevém e nabo sobre a habilidade competitiva da cultura da cevada. Ciência Rural, v. 44, n. 9, 2014. Disponível em: <http://dx.doi.org/10.1590/0103-8478cr20131633>. doi: 10.1590/0103-8478cr20131633.

VESALI, F.; OMID, M.; MOBLI, H.; KALEITA, A. Feasibility of using smart phones to estimate chlorophyll content in corn plants. Photosynthetica, v. 55, n. 4, p. 603-610, 2017. Disponível em: <https://link.springer.com/article/10.1007/s11099-016-0677-9>. doi: 10.1007/s11099-016-0677-9. 
VOGEL, G. F.; MARTINKOSKI, L.; RUZICKI, M. Efeitos da utilização de Azospirillum brasilense em poáceas forrageiras: importâncias e resultados. Agropecuária Científica no Semiárido, v. 10, p. 1-6, 2014. Disponível em: <http://revistas.ufcg.edu.br/acsa/index.php/ACSA/article/view/471>.

YANG, J.; KLOEPPER, J. W.; RYU, C. M. Rhizosphere bacteria help plants tolerate abiotic stress. Trends in Plant Science, v. 14, n. 1, p. 1-4, 2009. Disponível em: <https://doi.org/10.1016/j.tplants.2008.10.004> doi: 10.1016/j.tplants.2008.10.004. 